\title{
Confinement effectiveness of CFRP strengthened ultra-high performance concrete cylinders exposed to elevated temperatures
}

\author{
Aref A. Abadel ${ }^{1, *}$, Yousef R. Alharbi ${ }^{1}$ \\ ${ }^{1}$ Department of Civil Engineering, College of Engineering, King Saud University, Saudi Arabia
}

\begin{abstract}
Fire-related damage is an alarming concern to reinforced concrete (RC) structures throughout their service lives. When exposed to extreme temperatures, concrete can endure severe damage. Given that a complete replacement and/or demolition of fire-damaged structures can be an economic waste, a more viable option for extending the service life of the damaged structures involves repairing or strengthening the damaged members. Due to its more efficient qualities over conventional concrete, the use of concrete, such as ultra-high-performance concrete (UHPC) in the building industry, has dramatically grown in recent years. However, limited information is available about the confinement behavior of the unheated and heated UHPC members, particularly when wrapped with fiber-reinforced polymers (FRP). This paper investigates the effect of carbon fiber reinforced polymer (CFRP) sheet strengthening on the compressive strength of both UHPC and ultra-high-performance fiber reinforced concrete (UHPFRC). In this study, strengthening has been considered for the UHPC cylinders before and after they were subject to an elevated temperature of $400^{\circ} \mathrm{C}$, and they were left to cool by air cooling. Six UHPC mixes, which were made without the use of fibers, steel fibers (SF) alone, a hybrid system of SF and polyethylene alcohol (PVA), in addition to a hybrid system of steel, PVA, and polypropylene (PP) fibers were tested. Regarding the plain and various fiber-reinforced UHPC both at room temperature and after being exposed to $400^{\circ} \mathrm{C}$, the ultimate compressive strength of CFRP-confined concrete has shown an increase by $25 \%$ to $33 \%$ and $52 \%$ to $61 \%$, respectively compared with the unheated specimens.
\end{abstract}

Keywords: UHPC, UHPFRC, steel fiber, synthetic fiber, confinement of CFRP, high temperatures

\section{Introduction}

Owing to their exceptional mechanical properties and long-term durability, ultra-highperformance concrete (UHPC), and ultra-highperformance fiber reinforced concrete (UHPFRC) are widely utilized in the construction sector. Such improved characteristics have efficiently made the UHPC and UHPFRC products more desirable and attractive for utilization in important applications, such as precast bridge deck joints, bridge deck overlays, closure strips, and piles. Due to a better particle backing, these types of concrete exhibited better levels of decreased permeability and superior durability, and they achieved higher compressive strengths. When compared to concrete without fibers, the use of fibers in conventional concrete and UHPC can greatly improve ductility

\footnotetext{
*E-mail: aabadel@ksu.edu.sa; abade12002@hotmail.com
}

as stated in the available literature. Habel et al. [1] demonstrated that the development rate of mechanical properties of UHPFRC was highest for the modulus of elasticity, followed by the compressive and then the tensile strength. Ahmad et al. [2] conducted an experimental investigation on the behavior of UHPC under elevated temperature. The results showed an increase in compressive strength and toughness, while the flexural strength and modulus of elasticity decreased significantly with an increase in heat exposure duration. Guler et al. [3] proposed a predicted model for hybrid fiber reinforced concrete (RC), and the predictions of the proposed strength models were more accurate than the existing strength models available in the literature. Abadel et al. [4] found that strong fibers like steel fibers (SF) can restrain micro-crack growth, thus improving the strength of concretes, whereas relatively flexible fibers such as synthetic fibers improve material toughness 
by stress transfer mechanisms over larger crack openings. Guler et al. [5] examined the capacities of fiber-RC-filled square stub columns under axial loading. The result show that the hybrid fiber in concrete improved the ductility and toughness capacities of columns. Guler et al. [6], and Abadel et al. [7] highlighted the importance of the type and geometrical properties of hybrid fibers in reducing the spalling of concrete after being exposed to elevated temperature. The finding showed that using hybrid fibers in concrete reduced spalling and improved ductility.

The effect of high temperatures on the concrete's compressive strength and stiffness has been studied extensively [8-10]. Free water inside the concrete evaporates at high temperatures, especially when using concrete with higher strengths. However, water vapor stays within the concrete due to its thick structure. As a result, concrete surface spalling occurs. When discrete short synthetic fibers, such as polypropylene (PP) and polyethylene alcohol fiber (PVA) are uniformly distributed throughout the concrete, they improved the concrete spalling resistance when exposed to high temperatures $[7,11,12]$. Nevertheless, using different fibers of varying lengths to address the problem of various-sized cracks at different stages of concrete structure exploitation, can be an effective method to tackle these cracks $[4,13]$. In this regard, previous experimental studies on the use of hybrid fibers in UHPC to prevent explosive spalling are very limited [14]. Since UHPC has a brittle failure nature, the addition of synthetic fibers along with steel fibers plays a key role in reducing the spalling risk when exposed to elevated temperatures.

In general, concrete enjoys a good resistance when exposed to high temperatures compared to other construction materials, such as steel $[11,15$, 16]. However, when exposed to high temperatures, concrete degrades owing to the thermal spalling for plain concrete [17, 18] and fiber RC [19, 20]. As a result of fire, the ultimate load, stiffness, and ductility of these structural parts can be significantly reduced and, therefore, raising the issue that the heated damage structure requires strengthening. Exposure to high temperatures induced by fire is one of the most detrimental environmental effects on $\mathrm{RC}$ construction. Concrete is a non-flammable substance, but its many qualities are altered when exposed to elevated temperatures. Given that a complete replacement and/or demolition of firedamaged structures is an economic waste wasteful, a more viable option for extending their service life is to repair or strengthen the damaged concrete members. There are numerous strengthening techniques, including conventional methods (i.e., $\mathrm{RC}$ jacketing, steel jacketing), as well as modern techniques (i.e., fiber-reinforced polymer [FRP]), which can be used to upgrade the structural elements' axial load and ductility capability. Recently, the use of the FRP strengthening system for repairing and retrofitting structural elements has progressively grown due to several extraordinary properties, which include high strength and stiffness, low weight, ease of handling, design flexibility, excellent corrosion resistance, and long-term durability to harsh environmental conditions.

To date, numerous investigations have been undertaken to obtain an insightful understanding of the axial behavior of confined concrete. Moreover, experimental and analytical studies on FRP-wrapped low and normal strength concrete columns have been conducted by many researchers. However, FRP has also been explored as a method of external reinforcement for strengthening plain concrete columns [21], slender RC columns [22], short RC columns [23, 24], postheated RC columns [25, 26], and Geopolymer concrete columns [27]. The experimental results demonstrated that FRP has been successfully used to retrofit the deficiencies of concrete structural members significantly.

Although there have been several investigations on normal and high-strength concrete cylinders, which are strengthened by the FRP composite, comprehensive research remains limited on ultra-high performance concrete columns wrapped with FRP sheets. Mandal et al. [28] studied the response of FRP-wrapped circular concrete columns using different grades of concrete strength ranging from $26 \mathrm{MPa}$ to $81 \mathrm{MPa}$ under axial compression. The test results demonstrated that when normal strength concrete columns were strengthened by FRP sheets, their ultimate strength and ductil- 
ity were significantly increased compared to their unwrapped counterparts. However, the increase in strength and ductility is limited for high-strength concrete due to its poor dilation capacity.

Cui and Sheikh [29] conducted axial compression tests on cylindrical concrete columns using different grades of concrete strength ranging from $45 \mathrm{MPa}$ to $112 \mathrm{MPa}$. The results showed that as the strength of the unconfined concrete increased, the enhancement in strength, the capacity of energy absorption, and the ductility factor at rupture decreased dramatically. In the same vein, Zohrevand and Mirmiran [30] examined the uniaxial compression response of UHPC-filled FRP tubes with a variety of fiber types (carbon fiber reinforced polymer [CFRP] and GFRP). The compressive strength of the UHPC, which contains $2 \%$ steel fiber in volume, was $189 \mathrm{MPa}$ after 28 days. In comparison with high-strength concrete, the test findings indicated that UHPC demonstrated a considerable increase in uniaxial strength and strain of up to $98 \%$ and $195 \%$, respectively $v s$. the unconfined concrete specimens.

Saiidi et al. [31] demonstrated that UHPC has improved the capacity displacement, energy absorption, and damage tolerance in columns. Unlike normal concrete, confining high strength concrete has not substantially improved its strength or ductility because of its low dilatation tendency [28]. Conversely, due to its unique features, UHPC is projected to exhibit a greater capacity for dilatation, thereby achieving more efficient confinement behavior than high-strength concrete. Accordingly, analyzing the behavior of confined UHPC has become crucial for design optimization, which can contribute to developing recommendations regarding the confinement reinforcement amount required for UHPC concrete columns, particularly when exposed to different scenarios of mild-tosevere fire accidents. Wang et al. [32] have performed axial compression tests on UHPC cylinders, which are strengthened by CFRP and GFRP sheets. The test results showed that when enough FRP confinement is supplied, the UHPFRC can display ductile behavior. Lam et al. [33] have studied experimentally the axial response of the UHPC confined with the FRP system. The test findings re- vealed that the behavior of UHPC in compression was highly linear before the peak and very brittle after the peak. Besides, the specimens with FRP confinement are less effective for UHPC compared with the conventional concrete in terms of the enhancement of the ultimate strain and strength because the former has a higher strength with more brittleness in compression with the latter.

Based on the key applications that UHPC and UHPFRC are used for and considering that these are relatively new products, it is quite critical to understand the effect of FRP-wrapped on the performance of heated/unheated damaged UHPC and UHPFRC cylinder columns.

However, according to the reviewed literature, limited studies are available on the axial strength of FRP-confined heat-damaged UHPC. The purpose of this study is to assess experimentally the confinement response of CFRP strengthening of both unheated and heated damage plain and hybrid fiber-reinforced UHPC. For this purpose, different UHPC cylinders made with different fiber compositions were prepared and then exposed to elevated temperatures. All cylinder specimens were strengthened with a CFRP sheet and tested under axial compression. The compressive strength and stress-strain variation before and after strengthening and modes of failure of plain and hybrid fiberreinforced UHPC are discussed. Although the findings of previous studies on UHPC were limited and insufficient, the results of this study and the stateof-the-art literature revealed that UHPC exhibited a unique confinement behavior compared to conventional concrete and high-strength concrete.

Table 1. Mixture proportions of UHPC for $1 \mathrm{~m}^{3}$

\begin{tabular}{ll}
\hline Material & Weight $\mathbf{( k g / \mathbf { m } ^ { 3 } )}$ \\
\hline \hline Cement & 900 \\
Micro silica & 222 \\
Fine quartz sand & 1,000 \\
Water & 164 \\
Fiber & 100 \\
Super-plasticizer & 30 \\
\hline \multicolumn{2}{l}{ UHPC, ultra-high-performance concrete. }
\end{tabular}


Table 2. Physical and mechanical properties of fibers

\begin{tabular}{|c|c|c|c|c|c|c|}
\hline \multirow[t]{2}{*}{ Fiber type } & \multicolumn{6}{|c|}{ Properties of fibers } \\
\hline & $\begin{array}{l}\text { Length } \\
(\mathrm{mm})\end{array}$ & Shape & $\begin{array}{l}\text { Section } \\
\text { dimension }(\mathbf{m m})\end{array}$ & $\begin{array}{l}\text { Specific } \\
\text { gravity }\end{array}$ & $\begin{array}{l}\text { Tensile } \\
\text { strength } \\
\text { (MPa) }\end{array}$ & $\begin{array}{l}\text { Modulus of } \\
\text { elasticity } \\
\text { (GPa) }\end{array}$ \\
\hline SF & 30 & $\begin{array}{l}\text { Hooked } \\
\text { ends }\end{array}$ & $\Phi=0.55$ (Circular) & 7.85 & 1,345 & 200 \\
\hline Polyvinyl alcohol (PVA) & 30 & straight & $0.66 \phi$ (Circular) & 1.3 & 900 & 23 \\
\hline PP & 30 & straight & $0.022 \phi$ (Circular) & 0.90 & 550 & 4 \\
\hline
\end{tabular}

PP, polypropylene; SF, steel fibers.

Table 3. Fiber percent in different concrete mixes

\begin{tabular}{llll}
\hline Concrete mix & \multicolumn{3}{l}{ Fiber percentage by volume (by weight) } \\
& PP & SF & PVA \\
\hline \hline M0 & $0.0(0.00)$ & $0.0(0.00)$ & $0.0(0.00)$ \\
M1 & $0.0(0.00)$ & $1.0(3.27)$ & $0.0(0.00)$ \\
M2 & $0.0(0.00)$ & $0.7(2.29)$ & $0.3(0.16)$ \\
M3 & $0.1(0.04)$ & $0.7(2.29)$ & $0.2(0.00)$ \\
M4 & $0.0(0.00)$ & $0.7(2.29)$ & $0.2(0.11)$ \\
M5 & $0.0(0.00)$ & $0.5(1.64)$ & $0.5(0.27)$ \\
\hline
\end{tabular}

PVA, polyethylene alcohol; PP, polypropylene; SF, steel fibers.

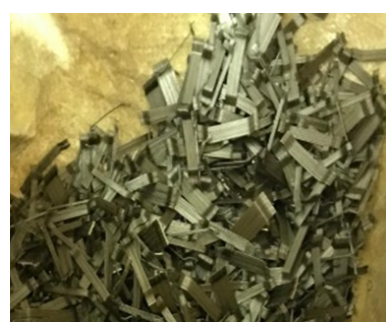

(a)

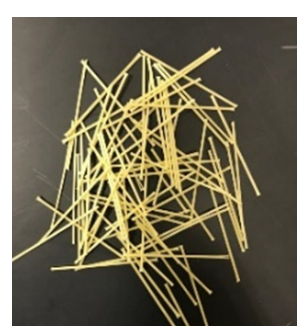

(b)

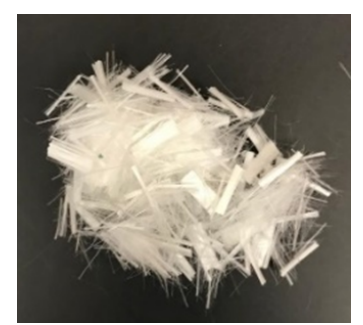

(c)

Fig. 1. Fibers used in the present study: (A) HookedSF; (B) PVA fibers (C) PP fibers. PVA, polyethylene alcohol; PP, polypropylene; SF, steel fibers

\section{Experimental program}

\subsection{Material properties and mixture pro- portions}

Portland ASTM Type-I cement has been utilized and the type of sand used in this study is quart sand with a nominal particle size of no $>2 \mathrm{~mm}$. The proportions of the mixture are listed in Table 1 . All the mix designs contained $900 \mathrm{~kg} / \mathrm{m}^{3}$ cement and $222 \mathrm{~kg} / \mathrm{m}^{3}$ micro silica. All mixtures contained $1,000 \mathrm{~kg} / \mathrm{m}^{3}$ sand. The water-to-binder ratio (w/b) in the entire combinations was 0.146 and the concrete workability has been maintained by adding $30 \mathrm{~kg} / \mathrm{m}^{3}$ of superplasticizer. In this study, three fiber types were evaluated, including steel, polyvinyl alcohol (PVA), and PP, as shown in Figure 1 . The characteristics of these fibers are presented in Table 2. The percentage by volume of fibers, which were used in each mix design, is provided in Table 3. 


\subsection{Test matrix}

In this study, the testing program focused on the effect of the CFRP sheet strengthening on the performance of the heat-damaged plain and fiberreinforced UHPC. The control (no-heat exposure), as well as the specimens, were exposed to hightemperature settings of $400^{\circ} \mathrm{C}$ for $3 \mathrm{~h}$. The temperature range and the exposure duration of the study have simulated the temperatures of exposure in the liner of the RC chimneys, clinker silos, and the containment vessels of the power plant [34, 35]. However, six concrete mix designs were examined, as illustrated in Table 3. The first mix was a UHPC control without fibers (M0), while the subsequent five mixes contained fibers (i.e., UHPFRC). Moreover, three various types of chopped fibers were used in producing UHPFRC, including SF, PP, and PVA fibers.

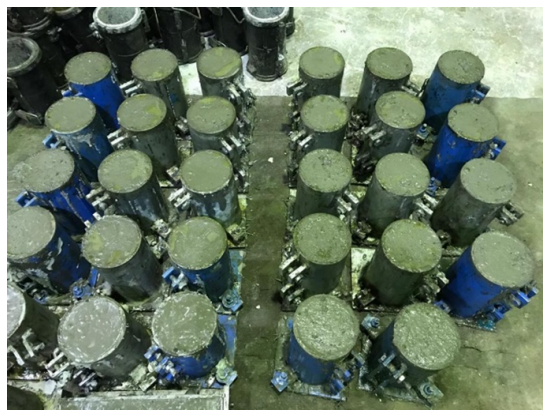

(a)

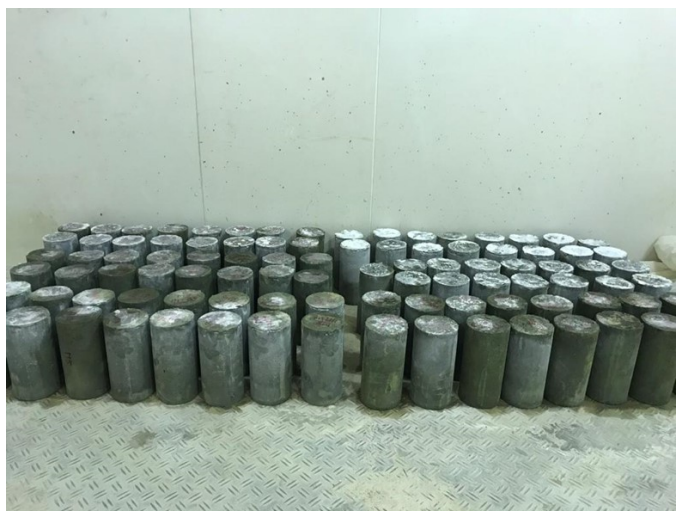

(b)

Fig. 2. Concrete cylinders; (A) during casting (B) after demolding

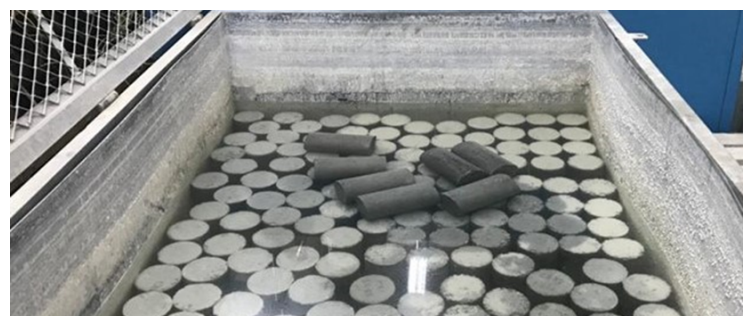

Fig. 3. Curing of concrete specimens in the water tank

Table 4. Fresh properties of UHPC

\begin{tabular}{lll}
\hline Mix No. & Slump (mm) & Unit weight $\mathbf{( k g / \mathbf { m } ^ { 3 } )}$ \\
\hline \hline M0 & 280 & 2,318 \\
M1 & 257 & 2,363 \\
M2 & 256 & 2,325 \\
M3 & 250 & 2,294 \\
M4 & 255 & 2,310 \\
M5 & 251 & 2,285 \\
\hline
\end{tabular}

UHPC, ultra-high-performance concrete.

\subsection{Preparation of specimens}

After mixing, the slump of the concrete was recorded, and the results are provided in Table 4. Plastic molds were utilized to create the concrete cylinder samples, whereby the concrete was poured into one layer. For the concrete prisms, the concrete was placed in steel molds. The filled molds are shown in Figure 2. After casting, the concrete surface was complete using a steel trowel. After $24 \mathrm{~h}$ of moist curing at room temperature, the concrete cylinders and prisms were demolded and cured in water up until 28 days, as shown in Figure 3.

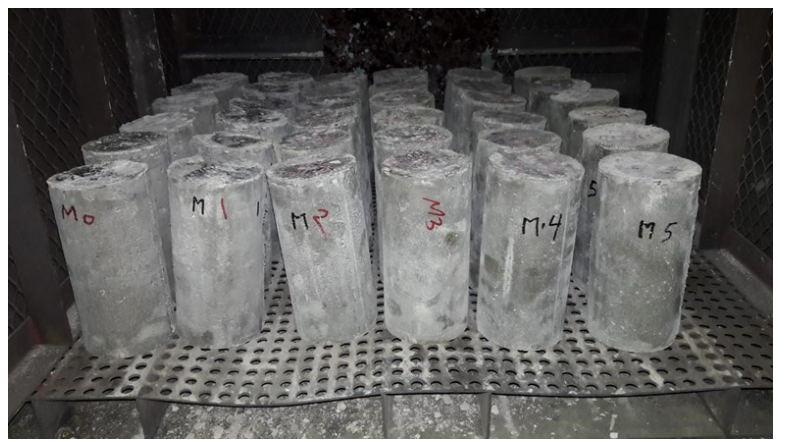

Fig. 4. Concrete cylinders inside the oven ready for heating 


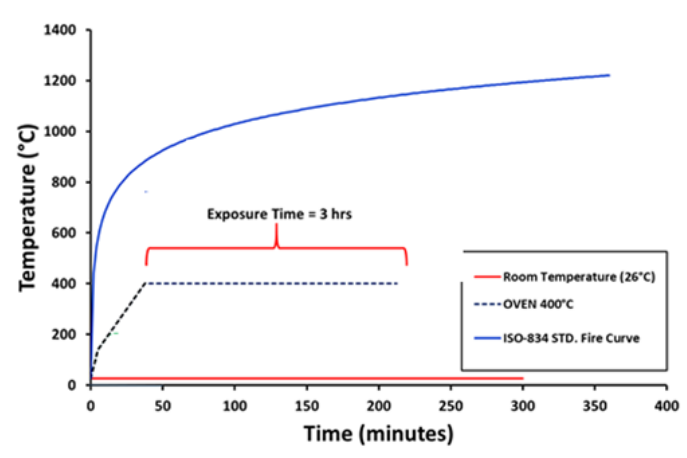

Fig. 5. Time-temperature curves used in this study

\subsection{Heating of specimens}

After 28-day water immersion, the concrete specimens were air-dried at room temperature for another 28 days to guarantee that the concrete was completely dry before being exposed to high temperatures. This has been carried out to allow drying shrinkage before the abrupt temperature increase caused by the high-temperature exposure. As shown in Figure 4, an electrical oven with an internal dimension of $1 \mathrm{~m} \times 1 \mathrm{~m} \times 1 \mathrm{~m}$ was used. The concrete specimens were heated at a rate of $8^{\circ} \mathrm{C} / \mathrm{min}$. The heating curves for each of the heating regimes was $400^{\circ} \mathrm{C}$ are shown in Figure 5, which includes the heating curve, as per ISO 834 [36] for comparison. A Type-K thermocouple was used to regulate the oven's temperature. When the oven temperature reached its maximum setting, the temperature was maintained for $3 \mathrm{~h}$. The concrete specimens were cooled to room temperature inside the oven after heating.

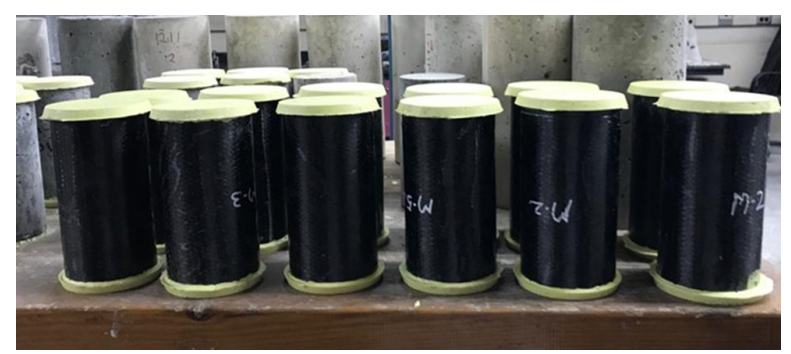

Fig. 6. Representative Concrete specimens after strengthened with CFRP sheet. CFRP, carbon fiber reinforced polymer
Table 5. Material properties for test specimens

\begin{tabular}{lll}
\hline Material & Properties & Values \\
\hline \hline CFRP & Thickness per layer $(\mathrm{mm})$ & 0.6 \\
material & $\begin{array}{l}\text { Ultimate tensile strength } \\
(\mathrm{MPa})\end{array}$ & 1,122 \\
& $\begin{array}{l}\text { Ultimate tensile strain } \\
\text { Tensile modulus of elasticity }\end{array}$ & $1.7 \%$ \\
& 68.9 \\
& $(\mathrm{GPa})$ \\
\hline Epoxy & Tensile strength (MPa) & 71.5 \\
adhesive & Tensile modulus of elasticity & 1.86 \\
for CFRP & $(\mathrm{GPa})$ \\
sheets & $\begin{array}{l}\text { Tensile strain at break 5.25\% } \\
\end{array}$ & $5.25 \%$ \\
& $\begin{array}{l}\text { Glass transition temperature } \\
\left({ }^{\circ} \mathrm{C}\right)\end{array}$ & 85 \\
& $\begin{array}{l}\text { Thermal decomposition tem- } \\
\text { perature }\left({ }^{\circ} \mathrm{C}\right)\end{array}$ & 345 \\
\hline
\end{tabular}

CFRP, carbon fiber reinforced polymer.

\subsection{Strengthening of specimens}

After heating, the cylinders were strengthened by using two layers of the CFRP sheet. Before applying the strengthening schemes, the surfaces of all the cylinder specimens were roughened using sandblasting to ensure a strong bond between the applied strengthening layer and the concrete surface. Additionally, before CFRP jacketing, the specimens' surfaces were lightly scratched to eliminate surface impurities. First, the specimen surface was properly cleaned to remove any dust. Next, the concrete's external surface was coated with an epoxy primer layer in the second step to fill the air voids and create a firm connection. Then, a thin coat of epoxy was applied to the concrete columns. After that, the CFRP layer was carefully wrapped. Special attention was paid to ensure that there were no air spaces between the fiber and the concrete surface. Before testing, the entire samples were maintained at room temperature for at least 28 days. Figure 6 shows the use of CFRP sheets to strengthen the cylinder specimens. The properties of the CFRP sheet are given in Table 5.

\subsection{Testing procedure}

The fresh properties of concrete were evaluated by using unit weight and slump flow. The 
properties of hardened concrete were also evaluated by using compressive strength. The compressive strength of concrete was measured according to ASTM C39 [37]. Before testing, sulfur capping was applied to the concrete cylinders to ensure a level testing surface. A compressometer, which comprised two LVDTs, has been used to measure the axial strain during the compressive strength test, as shown in Figure 7. Furthermore, a data acquisition system was used to record the readings of the load and deflections.

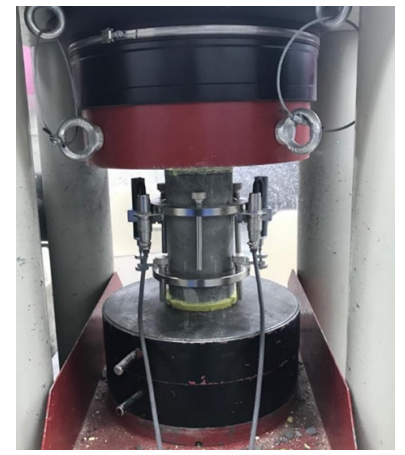

Fig. 7. Instrumented specimen ready for testing

\section{Results and discussion}

\subsection{Effect of heating on concrete speci- mens}

Figure 8 displays the concrete specimens after they were exposed to elevated temperatures. The discoloration was observed in the concrete specimens, which were heated to an elevated temperature of $400^{\circ} \mathrm{C}$. At a high temperature of $400^{\circ} \mathrm{C}$, the

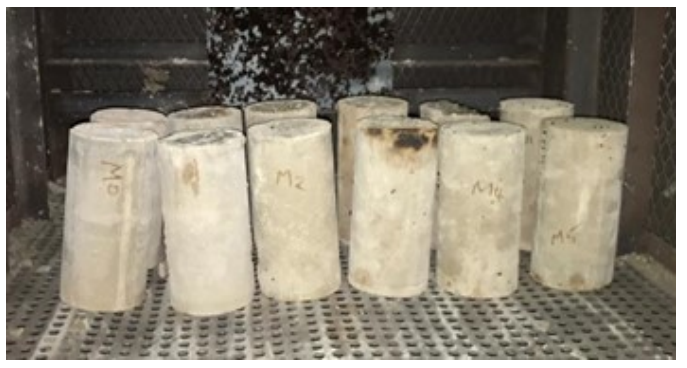

$400^{\circ} \mathrm{C}$

Fig. 8. View of representative specimens after heatingcooling cycle examined concrete specimens without SF (M0) and the concrete specimens with SF alone (M1) exhibited a slight surface spalling at the specimens' ends and corners. This spalling can be linked to the concrete's strong microstructure, making it difficult for water vapor to escape and, thus, leading to substantial internal pressure in certain locations. The absence of the PVA and PP fibers can also be a contributing factor because these fibers melt and evaporate at approximately $270^{\circ} \mathrm{C}$ and $170^{\circ} \mathrm{C}$, respectively, leaving venting canals that can reduce the internal vapor pressure (Phan, 2008). The concrete specimens, which were reinforced with PVA and PP fibers, demonstrated considerably less cracking and spalling compared with the specimens, which were reinforced without PVA and PP fibers.

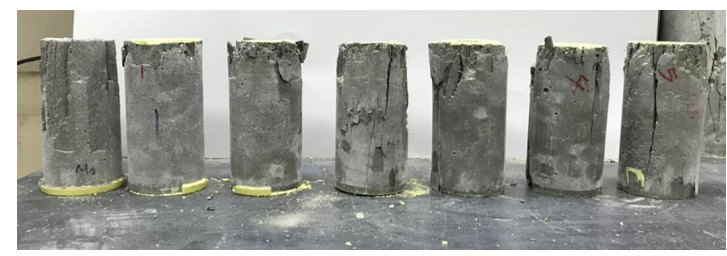

(a)

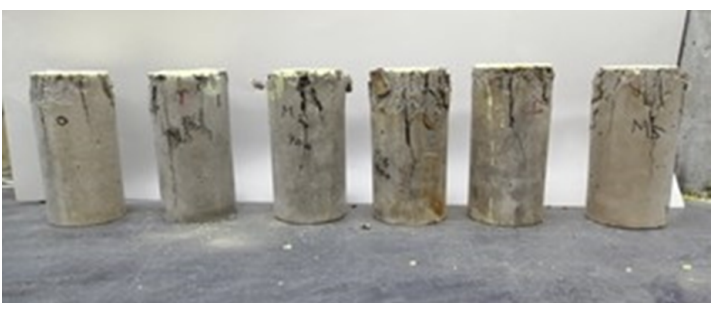

(b)

Fig. 9. View of representative specimens after compression testing: (A) $26^{\circ} \mathrm{C}$; (B) $400^{\circ} \mathrm{C}$

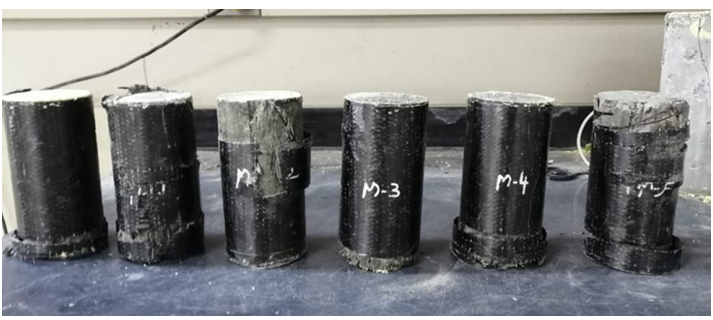

Fig. 10. CFRP rupture failure of confined postheated UHPC specimens. CFRP, carbon fiber reinforced polymer; UHPC, ultra-highperformance concrete 
Table 6. Test results summary of different UHPC mixes

\begin{tabular}{|c|c|c|c|c|}
\hline \multirow[t]{3}{*}{ Mix } & \multicolumn{4}{|c|}{ Compressive strength of concrete (MPa) } \\
\hline & \multicolumn{2}{|c|}{ Before strengthened } & \multicolumn{2}{|c|}{ After strengthened } \\
\hline & Room Temp. & $400^{\circ} \mathrm{C}$ & Room Temp. & $400^{\circ} \mathrm{C}$ \\
\hline M0 & 120.3 & $90.32(-24.6 \%)$ & $159.5(32.6 \%)$ & $139(53.9 \%)$ \\
\hline M1 & $139.8(16.2 \%)$ & $104.68(-25.12 \%)$ & $175.1(25.3 \%)$ & $167.2(59.2 \%)$ \\
\hline M2 & $134.6(11.8 \%)$ & $110.19(-18.2 \%)$ & $176.9(31.4 \%)$ & $167.5(52.0 \%)$ \\
\hline M3 & $131.7(9.5 \%)$ & $102.62(-21.5 \%)$ & $167.5(27.1 \%)$ & $158.2(54.2 \%)$ \\
\hline M4 & $128.2(6.8 \%)$ & $99.70(-22.3 \%)$ & $169.5(32.2 \%)$ & $150.2(50.7 \%)$ \\
\hline M5 & $127.8(6.5 \%)$ & $97.4(23.7 \%)$ & $163.8(28.2 \%)$ & $130.4(33.9 \%)$ \\
\hline
\end{tabular}

\subsection{Compressive strength}

The compressive strength test results of the UHPC specimens' pre- and post-strengthening are provided in Table 6 . Figures 9 and 10 show the obtained concrete cylinders after testing the compressive strength, and each value in Table 6 presents an average of the three cylinders. Moreover, the loss percentage of compressive strength in comparison with the primary compressive strength before being exposed to the heating regime is presented in Table 6. In general, the concrete specimens, which were exposed to high temperatures, recorded a lower compressive strength compared with those that were not exposed to high temperatures. The increase in the temperature decreased the residual compressive strength in all mixes regardless of fiber content or type.

Regarding the unheated concrete specimens (i.e., at room temperature), the use of SF increased the compressive strength by approximately $16 \%$ compared with the control mix (i.e., mix M0). When a hybrid PVA system and SF were used, the increase in the compressive strength ranged from $7 \%$ to $12 \%$ compared to the bare mix (i.e., mix M0). The concrete specimens, which were reinforced by using a hybrid system of steel, PVA, and PP fibers demonstrated a compressive strength improvement of approximately $10 \%$, as shown in Table 6 .

Regarding the heated concrete specimens at $400^{\circ} \mathrm{C}$, the use of a hybrid fiber system has been effective in increasing the residual compressive strength capacity after the heating exposure compared with the concrete specimens without any fibers. This can be attributed to the fibers' ability in controlling the thermal cracking and venting of the internal vapor pressure because PP and PVA fibers can melt and evaporate at high temperatures. The compressive strength tests on UHPC and UHPFRC revealed that the exposure to high temperatures of $400^{\circ} \mathrm{C}$ resulted in a considerable loss of strength. The compressive strength was reduced by approximately $24 \%$ in the control mix without fibers. A comparable decrease in compressive strength was observed in the concrete specimens, which were made of SF.

The use of a hybrid fiber system instead of SF has enhanced the residual compressive strength. The decrease in the compressive strength of the concrete specimens made of a hybrid system, which consists of steel and PVA fibers ranged between $18 \%$ and $24 \%$. The concrete specimens, which were reinforced by using a hybrid system of steel, PVA, and PP fibers demonstrated a compressive strength loss of about $22 \%$.

\subsection{Mode of failure}

Figure 10 displays the failure modes of the concrete's compressive strength specimens before and after being exposed to a high temperature of $400^{\circ} \mathrm{C}$. The failure of the unconfined UHPC specimens was brittle, with a quick load reduction after 
the peak load was attained. The UHPC specimens, which were made with or without fibers and exposed to room temperature showed more brittle and failure in an explosive nature compared with similar concrete mixes, which were exposed to $400^{\circ} \mathrm{C}$. In general, the failure mode was more ductile in the concrete specimens, which were made of fibers and exposed to high temperatures at $400^{\circ} \mathrm{C} v s$. the concrete specimens without fibers. The concrete specimens, which were made with a hybrid system of PP and PVA fiber showed the greatest ductile behavior in comparison with all the concrete mixes. This can be attributed to the melting and evaporation of the PP and PVA fibers, causing increased concrete porosity.

Figure 10 shows the representative samples of failure modes because of the compression tests of all types of concrete confined cylinders. All the strengthened specimens failed due to a quick and violent rupture of the CFRP sheets. The jacket has mainly failed because of the vertical and diagonal cracks. With an increasing load, the fissures become wider. Additionally, a noise was heard as the load increased, and failure occurred at the top and bottom of the specimens, while others failed in the mid-height of the specimens, as shown in Figure 10 for the unheated and heated specimens. In this region, the stress sensitivity was because of the release of high energy in the form of brittle failure of the CFRP sheets. The damaged specimens showed good contact between the concrete and the CFRP jackets, and there was no de-bonding.

\subsection{Stress-strain curves}

Evaluating the stress-strain relation of concrete is crucial, particularly when the concrete is exposed to elevated temperatures. Figure 11(a) and 11(b) show the stress-strain curves of the concrete specimens, which were exposed to $26^{\circ} \mathrm{C}$ and $400^{\circ} \mathrm{C}$, respectively.

As shown in these figures, the concrete specimens, which were exposed to room temperature, had a higher elastic modulus compared with their corresponding concrete mixtures, which were exposed to a high temperature of $400^{\circ} \mathrm{C}$. The concrete mixture's modulus of elasticity, which was subject to $400^{\circ} \mathrm{C}$, was the lowest in comparison with corresponding concrete mixes, which were exposed to room temperature. The concrete mixes, which were heated to $400^{\circ} \mathrm{C}$, demonstrated an increased ductility and energy dissipation. It has also been observed that when the UHPFRC specimens were exposed to an elevated temperature of $400^{\circ} \mathrm{C}$, the stiffness loss was greater than the compressive strength reduction, probably because of the deterioration of the concrete matrix and the formation of thermal cracks. UHPFRC reinforced with SF exhibited a higher elastic modulus and energy absorption (i.e., area under the stress-strain curve) compared with the concrete specimens without fibers or hybrid UHPFRC. This has been expected, given that SF have a higher tensile strength and modulus of elasticity than the PVA or PP fibers. Additionally, SF are more resistant to high temperatures than PVA and PP fibers. The stress-strain relationships of the unheated and heated concrete specimens showed that the modulus of elasticity decreased as the temperature exposure increased from an ambient temperature to an elevated temperature of $400^{\circ} \mathrm{C}$, as shown in Figures 11 (b) and 12 (b). The stress-strain curves for all strengthened specimens with CFRP showed that the ultimate axial and lateral strains increased substantially, thereby indicating enhanced ductility. Such a significant enhancement in ductility is owing to significant confinement to micro-cracked heat-damaged specimens.

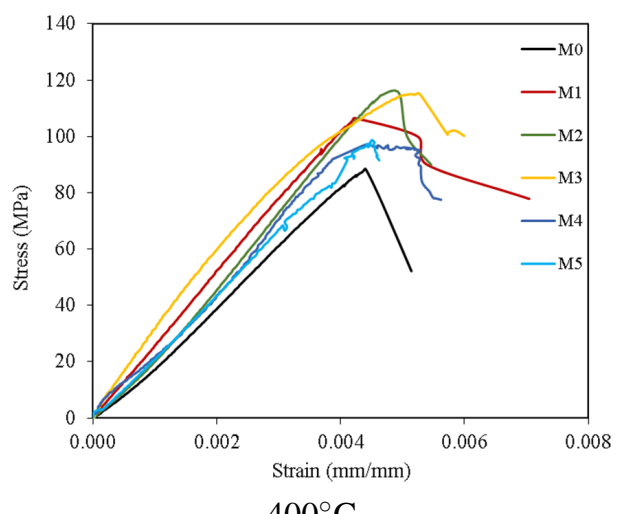

Fig. 11. Stress-strain curves for UHPFRC cylinders before and after temperature exposure to $400^{\circ} \mathrm{C}$. UHPFRC, ultra-high-performance fiber reinforced concrete 


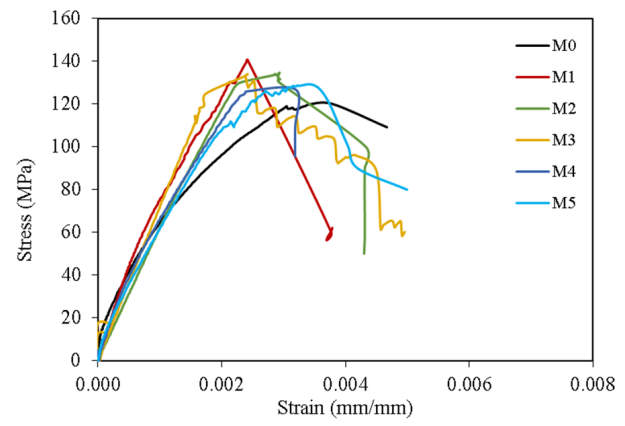

(a) Room temperature

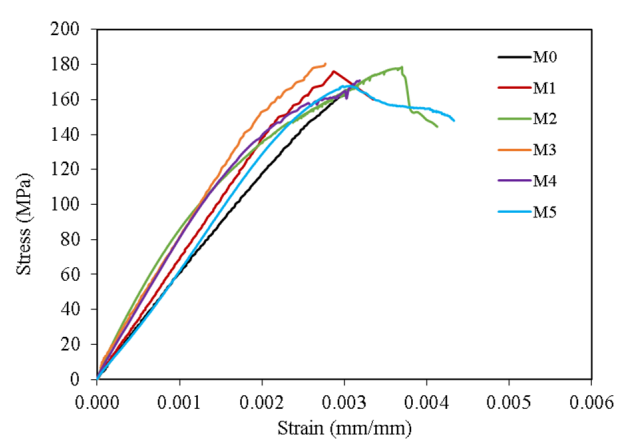

(b)

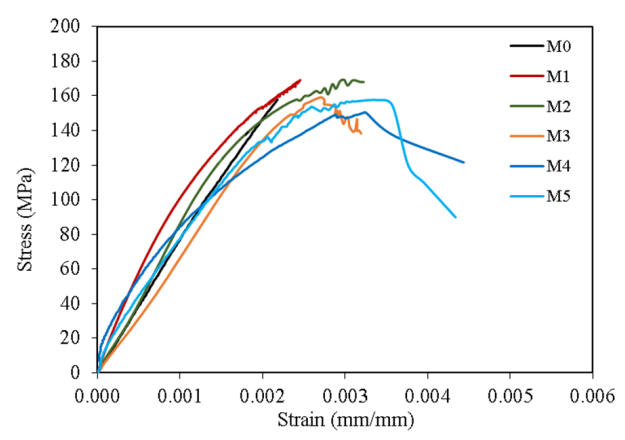

(c)

Fig. 12. Stress-strain curves for UHPC specimens before and after strengthened: (A) Case of no fibers; (B) Case of SF alone. UHPC, ultra-highperformance concrete

\subsection{Effect of types of fiber}

The exposure temperatures were plotted $v s$. the normalized UHPC and UHPFRC strength after strengthened (i.e. the ratio of the residual strength of UHPC after high-temperature exposure to the UHPC strength at room temperature) for different fiber types to investigate the effect of fiber type and combination on the performance of test specimens after high-temperature exposure, as shown in Figure 13. The addition of fibers in the plain of UHPC has a considerable impact on the residual compressive strength of concrete, as seen in these data. The inclusion of fibers in the concrete mixture significantly reduced the loss of compressive strength caused by high temperatures. As a result, post-heated UHPFRC cylinders lose significantly less residual compressive strength than plain UHPC specimens. When compared to SF alone and the hybrid system consisting of steel and PVA fibers, the hybrid fiber system consisting of steel, PVA, and PP fibers was the most successful in preserving compressive strength at $400^{\circ} \mathrm{C}$. The superior behavior of PP as well as PVA fibers can be attributed to their melting at high temperatures, which produced channels inside the concrete matrix [38].

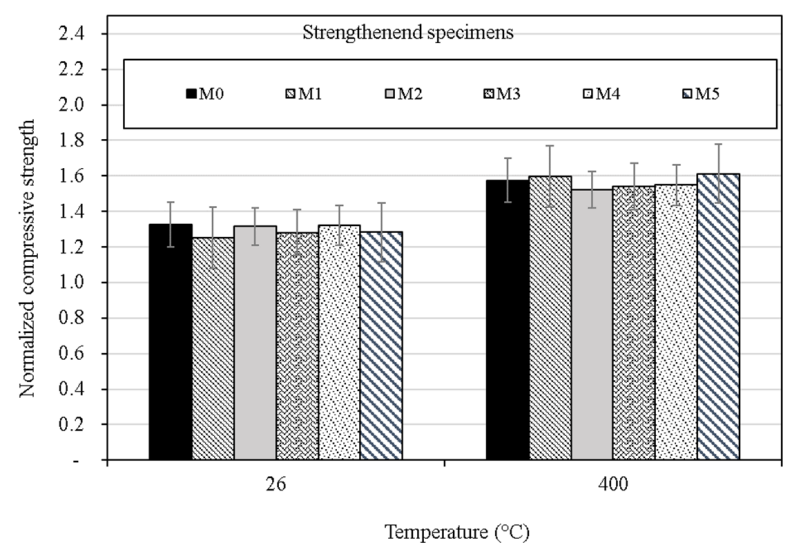

Fig. 13. Confined to unconfined compressive strength comparisons for UHPC and UHPFRC specimens. UHPC, ultra-high-performance concrete; UHPFRC, ultra-high-performance fiber reinforced concrete

\subsection{Effect of strengthening on compres- sive strength of un-heated and heated speci- mens}

The effect of CFRP wrapping on the behavior of stress-strain response of heated-damaged UHPC has been clearly observed. After exposure to high temperatures, the strength and ductility of concrete were significantly increased. The CFRP wrapping can restore the original compressive strength at room temperature even after $3 \mathrm{~h}$ of exposure at 
$400^{\circ} \mathrm{C}$, but the modulus of elasticity cannot be restored due to the confinement effect on the modulus of elasticity of heated-damaged concrete, which was minimal, particularly with a limited number of layers. Moreover, for all the specimens with and without fibers, the results of the ultimate strain of CFRP confined concrete tended to increase with the fire damage level.

Figure 12 shows the effect of the wrapping scheme on the stress-strain curves of all the UHPC specimens before and after strengthening at room temperature and varying elevated temperatures. Obviously, this demonstrates that the strength and ductility of all the mix types improved considerably; it has been more obvious for the specimens, which were exposed to elevated temperatures.

Figure 13 shows the influence of temperature exposure on the residual compressive strength of heated-damaged concrete. The ratio of increased with the temperature exposure. The effect of exposure was more obvious on the grade of normal strength, and the greatest effect exposure was for the high strength concrete.

It is, therefore, obvious that the strength improvement level by CFRP confinement for heateddamaged UHPC was greater in comparison with the unheated concrete. The confinement effectiveness increased with the level of heated damage, especially for the UHPFRC specimen.

The CFRP wrapped cylinders showed higher compressive strengths compared to the unwrapped specimens. This increase ranged between $25 \%$ and $32 \%$ for UHPC and UHFRP wrapped specimens. This indicates that the confinement effectiveness of UHPC using CFRP sheets was more effective in increasing the capacity of the concrete columns. Regarding the post-heated specimens, they showed a significant increase in compressive strength after being strengthened with two layers of the CFRP sheets. The increase ranged between $33 \%$ and $59 \%$ for all concrete types. It was observed that enhancing the strength and ductility of heat-damaged cylinders, which were wrapped in two layers of CFRP sheets was more effective in retrofitting the ultimate load capacity of UHPC and UHPFRC cylinders. The axial and lateral ultimate strains increased considerably, exhibiting ductility improvement - this improvement in ductility can be attributed to significant confinement to microcracked heated-damaged concrete cylinders.

\section{Conclusion}

Based on the results of this study, the following findings can be derived:

1. The responses of the unconfined UHPC were highly linear before the peak and extremely brittle beyond the peak, which is consistent with the results of the previous testing on the unconfined UHPC.

2. The use of PP and PVA fibers, combined with steel fiber has improved the mechanical properties of concrete. This can be attributed to the melting and evaporation of the above-mentioned fibers at high temperatures, thereby creating venting channels that reduce the internal vapor pressure.

3. No noticeable change has been observed in the ultimate strength and the elastic modulus of UHPFRC in comparison with UHPC. However, the post-peak part in the stressstrain curve has substantially been affected by the increase in the fiber content. For the same volume of steel fiber, a higher aspect ratio may lead to a more efficient improvement of post-peak behavior.

4. Most UHPC and UHPFRC wrapped specimens failed with the rupture of CFRP sheets at or near the mid-height.

5. Regarding the UHPC and UHPFRC specimens with or without fibers, CFRP composites can be utilized as an effective strengthening technique for increasing the axial load carrying capacity of non-heated and heated-damaged concrete cylinders. As has been observed, the ductility was more visible in heat-damaged specimens, which were strengthened by CFRP jackets compared with the unheated strengthened specimens.

6. The CFRP wrapped cylinders demonstrated higher compressive strengths compared to the unwrapped specimens. The obtained in- 
crease ranged between (25-32\%) and (33$59 \%$ ) for the non-heated and heated UHPC specimens, respectively.

7. The CFRP confinement has inflicted a greater effect on enhancing the strength of heated-damaged concrete compared with its effect on undamaged concrete. The effectiveness increased in a direct proportion to the degree of thermal damage. However, the stiffness of the heat-damaged specimen could not be restored by the CFRP strengthening scheme with two layers of CFRP sheets.

\section{Declaration of competing interest}

None.

\section{Acknowledgements}

The authors extend their appreciation to Researchers Supporting Project number (RSP-2021/343), King Saud University, Riyadh, Saudi Arabia.

\section{References}

[1] Habel K, Viviani M, Denarié E, Brühwiler E. Development of the mechanical properties of an Ultra-High Performance Fiber Reinforced Concrete (UHPFRC). Cem Concr Res. 2006;36:1362-70. https://doi.org/10. 1016/J . CEMCONRES . 2006.03.009

[2] Ahmad S, Rasul M, Adekunle SK, Al-Dulaijan SU, Maslehuddin M, Ali SI. Mechanical properties of steel fiber-reinforced UHPC mixtures exposed to elevated temperature: Effects of exposure duration and fiber content. Compos Part B. 2019;168:291-301. https:// doi . org/10.1016/J . COMPOSITESB . 2018.12.083

[3] Guler S, Yavuz D, Korkut F, Ashour A. Strength prediction models for steel, synthetic, and hybrid fiber reinforced concretes. Struct Concr. 2019;20:428-45. https://doi.org/10.1002/SUC0.201800088

[4] Abadel A, Abbas H, Almusallam T, Al-Salloum Y, Siddiqui N. Mechanical properties of hybrid fibrereinforced concrete - analytical modelling and experimental behaviour. Mag Concr Res. 2016;68:823-43. https: //doi .org/10.1680/JMACR . 15.00276

[5] Guler S, Yavuz D, Aydın M. Hybrid fiber reinforced concrete-filled square stub columns under axial compression. Eng Struct. 2019;198:109504. https : //doi. org/10. 1016/J .ENGSTRUCT . 2019.109504

[6] Guler S, Akbulut ZF, Siad H, Lachemi M. Effect of macro polypropylene, polyamide and steel fibers on the residual properties of SCC at ambient and elevated temperatures. Constr Build Mater. 2021;289:123154 https : //doi .org/10.1016/J . CONBUILDMAT . 2021.123154
[7] Abadel A, Elsanadedy H, Almusallam T, Alaskar A, Abbas H, Al-Salloum Y. Residual compressive strength of plain and fiber reinforced concrete after exposure to different heating and cooling regimes. Eur J Environ Civ Eng. 2021;1-20. https://doi.org/10. 1080/19648189. 2021.1960898

[8] Poon CS, Azhar S, Anson M, Wong YL. Comparison of the strength and durability performance of normaland high-strength pozzolanic concretes at elevated temperatures. Cem Concr Res. 2001;31:1291-300. https : //doi.org/10.1016/S0008-8846(01) 00580-4

[9] Bastami M, Chaboki-Khiabani A, Baghbadrani M, Kordi M. Performance of high strength concretes at elevated temperatures. Sci Iran. 2011;18:1028-36. https : //doi .org/10.1016/J. SCIENT . 2011.09.001

[10] Khan MS, Abbas H. Performance of concrete subjected to elevated temperature. Eur J Environ Civ Eng. 2015;20:532-43. https://doi.org/10.1080/ 19648189.2015. 1053152

[11] Kalifa P, Chéné G, Gallé C. High-temperature behaviour of HPC with polypropylene fibres: From spalling to microstructure. Cem Concr Res. 2001;31:1487-99. https://doi.org/10.1016/S0008-8846(01) 00596-8

[12] Bangi MR, Horiguchi T. Effect of fibre type and geometry on maximum pore pressures in fibre-reinforced high strength concrete at elevated temperatures. Cem Concr Res. 2012;42:459-66. https://doi.org/10. 1016/J . CEMCONRES . 2011.11.014

[13] Almusallam T, Ibrahim SM, Al-Salloum Y, Abadel A, Abbas H. Analytical and experimental investigations on the fracture behavior of hybrid fiber reinforced concrete. Cem Concr Compos. 2016;74:201-17. https ://doi . org/10.1016/J . CEMCONCOMP . 2016.10.002

[14] Yermak N, Pliya P, Beaucour AL, Simon A, Noumowé A. Influence of steel and/or polypropylene fibres on the behaviour of concrete at high temperature: Spalling, transfer and mechanical properties. Constr Build Mater. 2017;132:240-50. https://doi.org/ 10.1016/J . CONBUILDMA T . 2016.11.120

[15] Noumowé A, Carré H, Daoud A, Toutanji H. Highstrength self-compacting concrete exposed to fire test. J Mater Civ Eng. 2006;18:754-8. https://doi .org/ 10.1061/ (ASCE) 0899-1561 (2006) 18:6 (754)

[16] Phan L. Spalling and mechanical properties of high strength concrete at high temperature. Actes Des Journées Scientifiques Du LCPC. 2007:1595-608.

[17] Chan SY, Peng GF, Chan JK. Comparison between high strength concrete and normal strength concrete subjected to high temperature. Mater Struct. 1996;29:6169. https://doi .org/10.1007/BF02485969

[18] Aslani F, Bastami M. Constitutive relationships for normal-and high-strength concrete at elevated temperatures. ACI Mater J. 2011;108:355-64. https : //doi . org/10.14359/51683106

[19] Lau A, Anson M. Effect of high temperatures on high performance steel fibre reinforced concrete. Cem 
Concr Res. 2006;36:1698-707. https://doi.org/ 10.1016/J . CEMCONRES . 2006.03.024

[20] Varona FB, Baeza FJ, Bru D, Ivorra S. Influence of high temperature on the mechanical properties of hybrid fibre reinforced normal and high strength concrete. Constr Build Mater. 2018;159:73-82. https://doi.org/10. 1016/J . CONBUILDMAT . 2017. 10.129

[21] Elsanadedy HM, Al-Salloum YA, Alsayed SH, Iqbal RA. Experimental and numerical investigation of size effects in FRP-wrapped concrete columns. Constr Build Mater. 2012;29:56-72. https://doi.org/10.1016/ J . CONBUILDMA T . 2011 . 10.025

[22] Al-Salloum YA, Al-Amri GS, Siddiqui NA, Almusallam TH, Abbas $\mathrm{H}$. Effectiveness of CFRP strengthening in improving cyclic compression response of slender RC columns. J Compos Constr. 2018;22:04018009. https://doi.org/10.1061/ (ASCE) CC. 1943-5614.0000842

[23] Thériault M, Neale KW. Design equations for axially loaded reinforced concrete columns strengthened with fibre reinforced polymer wraps. Can J Civ Eng. 2011;27:1011-20. https://doi .org/10.1139/ L00- 019

[24] Demers M, Neale KW. Confinement of reinforced concrete columns with fibre-reinforced composite sheets an experimental study. Can J Civ Eng. 2011;26:226-41. https://doi.org/10.1139/L98-067

[25] Al-Salloum YA, Almusallam TH, Elsanadedy HM, Iqbal RA. Effect of elevated temperature environments on the residual axial capacity of $\mathrm{RC}$ columns strengthened with different techniques. Constr Build Mater. 2016;115:345-61. https : //doi .org/ 10.1016/J . CONBUILDMAT . 2016.04.041

[26] Abadel AA, Khan MI, Masmoudi R. Axial capacity and stiffness of post-heated circular and square columns strengthened with carbon fiber reinforced polymer jackets. Structures. 2021;33:2599-610. https :// doi .org/10.1016/J. ISTRUC . 2021.05.081

[27] Alrshoudi F, Abbas H, Abadel A, Albidah A, Altheeb A, Al-Salloum Y. Compression behavior and modeling of FRP-confined high strength geopolymer concrete. Constr Build Mater. 2021;283:122759. https : //doi .org/ 10.1016/J . CONBUILDMAT . 2021. 122759

[28] Mandal S, Hoskin A, Fam A. Influence of concrete strength on confinement effectiveness of fiber-reinforced polymer circular jackets. Struct J. 2005;102:383-92. https://doi.org/10.14359/14409
[29] Cui C, Sheikh SA. Experimental study of normaland high-strength concrete confined with fiberreinforced polymers. J Compos Constr. 2010;14:55361. https://doi.org/10.1061/(ASCE)CC . 1943-5614.0000116

[30] Zohrevand P, Mirmiran A. Behavior of ultrahighperformance concrete confined by fiber-reinforced polymers. J Mater Civ Eng. 2011;23:1727-34. https:// doi.org/10.1061/ (ASCE) MT . 1943-5533.0000324

[31] Saiidi MS, O’Brien M, Sadrossadat-Zadeh M. Cyclic response of concrete bridge columns using superelastic nitinol and bendable concrete. Struct J. 2009;106:69-77. https://doi.org/10.14359/56285

[32] Wang W, Wu C, Liu Z, Si H. Compressive behavior of ultra-high performance fiberreinforced concrete (UHPFRC) confined with FRP. Compos Struct. 2018;204:419-37. https : //doi.org/10.1016/J. COMPSTRUCT.2018.07.102

[33] Lam L, Huang L, Xie JH, Chen JF. Compressive behavior of ultra-high performance concrete confined with FRP. Compos Struct. 2021;274:114321. https : //doi . org/10.1016/J . COMPSTRUCT . 2021 . 114321

[34] Khan MS, Prasad J, Abbas H. Shear strength of $\mathrm{RC}$ beams subjected to cyclic thermal loading. Constr Build Mater. 2010;24:1869-77. https : //doi .org/ 10.1016/J . CONBUILDMA T . 2010.04.016

[35] Khan MS, Prasad J, Abbas H. Bond strength of RC beams subjected to cyclic thermal loading. Constr Build Mater. 2013;38:644-57.https ://doi .org/10.1016/ J. CONBUILDMAT . 2012.09.018

[36] ISO. Fire-resistance tests - elements of building construction - part 1: General requirements. vol. ISO 834-1: 1999.

[37] ASTM-C39. Standard test method for compressive strength of cylindrical concrete. Annual Book of ASTM Standards 2010. https ://doi .org/D.0.I:10.1520/ C0039_C0039M-10

[38] Komonen J, Penttala V. Effects of high temperature on the pore structure and strength of plain and polypropylene fiber reinforced cement pastes. Fire Technol. 2003;39:23-34. https://doi.org/10.1023/A : 1021723126005
Received 2021-11-20 Accepted 2022-01-12 